\title{
Consider This--Deciding whether an Organization Is Ethical or Not: A Policy Capturing Approach
}

\author{
D. Scott Kiker ${ }^{1}$, Julie Fugate ${ }^{1}$, Mary B. Kiker ${ }^{1} \&$ Judith S. Callahan $^{2}$ \\ ${ }^{1}$ Department of Business Administration, Auburn University at Montgomery, Montgomery, Alabama, USA \\ 2 Department of Management, College of Business Administration, University of Florida, Gainesville, Florida, USA \\ Correspondence: D. Scott Kiker, Department of Business Administration, Auburn University at Montgomery, \\ Montgomery Alabama, 36124-4023, USA. Tel: 1-334-244-3313. E-mail: skiker1@aum.edu
}

Received: September 8, 2015

Accepted: September 23, 2015

Online Published: October 22, 2015

doi:10.5430/ijba.v6n6p1

URL: http://dx.doi.org/10.5430/ijba.v6n6p1

\begin{abstract}
Organizational ethics has been a key topic in the popular media for decades. Research has responded by exploring internal perceptions of ethics and ethical behavior of leaders and others in the organization. The perceptions of external constituencies have remained largely unexamined. In this research, we rely on the ethics literature to identify variables that may be considered by external constituencies when making generalizations about an organization's ethical behavior. Employing a policy capturing approach, we asked subjects to read a series of organizational profiles that varied in reported level of ethics in leadership, climate, human resources, philanthropy and strategic philanthropy. Our results reveal that external observers of organizations require information on multiple variables to evaluate an organizational as (un)ethical. Further, this information is used in different ways depending on the dependent variable under consideration.
\end{abstract}

Keywords: organizational ethics, business ethics, external perspective, policy capturing research

\section{Introduction}

A recent issue of Fortune Magazine (September 2015) led with the cover story, "Our first ever 'Change the World' list." Identified are 51 companies that 'do good by doing well.' These companies are recognized for making significant progress in addressing major social woes as part of their business strategy. One caveat offered alluded to a highly skeptical public of the "goodness" of any business by stating that large diversified multinational corporations may be "...ameliorating one great global problem even as they contribute to another (p. 59)." Thus, even companies recognized for effective and important philanthropic efforts are viewed askance by the public.

One theoretical perspective on business ethics adheres firmly to the statement that ethical organizations do not exist. Ethics, proponents of this view say, resides in the individual (Collier, 1998). Yet, practically speaking, those who observe the business landscape anthropomorphize. The collective that is the organization is imbued with human characteristics, including ethics. Recent qualitative and quantitative literature reviews show the progress made in understanding the collective, but the lens has been focused inward - on employees. We cast a wider net, attempting to understand how those very factors that influence employees also influence people outside the organization.

Understanding how non-employees develop perceptions of the ethical organization has important implications for organizations as they court investors, seek to attract new employees, and manage the image of the organization through press releases and media coverage. Through a richer understanding of how people develop perceptions of the ethical organization, decision makers may engage in more effective decision making regarding the framing and presentation of information to the public.

Discourse on business ethics may be heard in boardrooms, lunchrooms and classrooms. Socially conscious consumers and idealistic employees expect more from companies than merely providing quality goods or services at a fair price; businesses must do so ethically. Despite the apparent omnipresence of business ethics discussions, the concept of the 'ethical organization' is relatively new (Collier, 1998).

Prior to the 1970s, the empirical study of ethics was limited, and a vast gap existed between the theoretical and applied research. Companies were given a tacit license to operate in society in exchange for their goods and services. As companies grew ever larger and competition among them increased, the legal authorities stepped in: assessing 
heavy anti-trust fines on companies like Levi Straus, demanding the divestiture of AT\&T, and creating the "baby bells." Later, terms such as "downsizing" and "rightsizing" entered the lexicon. The tension between the public good and companies grew.

Today, financial maleficence, illegal discrimination, sending jobs overseas, and the massive disparity between CEO pay and the average worker salary are making headlines. These and other corporate actions have compounded the already cynical view of business by the public, who now demand companies go beyond simply following the rules (laws) in their pursuit of economic profit. Businesses are now measured with an 'ethical yardstick' where each is expected to meet an ethical standard while implementing their business model and (increasingly) "give back" to society through philanthropic initiatives. And while recent literature has examined a host of intra-organizational factors, we know of no research that has attempted to capture the influence of these factors on the external constituency's view of the ethical organization.

\section{Origins of the Perceptions of the Ethical Organization}

The social contract between business and society has changed, and companies are now attending to perceptions of the public. This has motivated companies to behave in ways that yield favorable ethical assessments by their constituents. This may be seen in the substantial financial investment made by companies in ethics compliance, education and training (Schminke, Caldwell, Ambrose \& McMahon, 2014), image marketing, and focused philanthropy.

To be sure, some of the motivation to engage in ethical practices results from neither a desire to avoid negative repercussions nor to obtain positive outcomes for the firm. After all, ethical organizational behavior is merely the collective-level processes of individuals, and many individuals are motivated to behave ethically simply because they believe it is the "the right thing to do" (Collier, 1998; Kohlberg, 1969). However, in the absence of (and in addition to) this desire to do right, organizations also fear that any perceived ethical misstep will be swiftly exposed and result in a variety of negative consequences.

This fear is not unfounded. The instantaneous and world-wide sharing of information via the internet has served to spotlight organizational ethical lapses. Moreover, we have witnessed the formation and growth of vocal and active groups taking a stand against unethical companies. These groups are growing in number, and they have adopted more aggressive and effective tactics to bring pressure on organizations to behave ethically (Porter \& Kramer, 2006). Beyond this unwanted negative attention, there may also be negative economic consequences. Research reveals that consumers' intentions to purchase fall dramatically after an ethical lapse comes to light (Trudel, 2004). While this research reports behavioral intentions rather than behavioral outcomes, other research suggests that ethical lapses result in negative economic consequences for firms. Consider the fallout associated with the unethical behavior of the former United Way President, William Armony. He resigned amid allegations of misappropriation of corporate funds which he used to support an extravagant lifestyle. Donations to the organization fell by $\$ 66$ million in the year following the scandal and remained low for many years to follow (Johnston, D.C, 1997, as reported in Trevino \& Nelson, 2004).

Companies also fear calls for government actions if they are not perceived to be behaving ethically (Nussbaum, 2002). Consider the Sarbanes-Oxley Act of 2002: many of the provisions, such as placing restrictions on the timing of top executives' stock sales and the requirement that company CFOs certify the accuracy of company financial statements (with severe penalties tied to falsification of these statements), likely resulted from public sentiment at the time (Trevino \& Nelson, 2004). Conversely, if constituents perceive a company to be behaving ethically, positive outcomes for the firm might be expected. While available data are not conclusive, some evidence points to a positive, bottom-line return for those organizations that have a reputation for behaving ethically. For example, a past President of Johnson and Johnson assembled a list of companies with a reputation for ethical behavior and compared market returns of these companies with the overall S\&P index over a forty year period. His results showed that companies categorized as behaving ethically had returns of $11.2 \%$ between 1940 and 1990 compared to the overall S\&P index average return of $6.2 \%$ for the same period (Labitch, 1992, as reported in Trevino \& Nelson, 2004). Further, research suggests that organizational ethics may help attract and retain an effective workforce. In one study, trust in the company and its managers, honest company communications, and respectful treatment of workers was ranked among the top goals of employees (Trevino \& Nelson, 2004). Interestingly, these ranked ahead of even pay and job security (SHRM, 2015).

Other benefits of being perceived as ethical include building up what Trevino and Nelson (2004) call a "trust reserve" with both trading partners and customers. For example, if two organizations are deemed to be trustworthy, there are more options available for these companies to make potentially beneficial long-term contracting deals with one 
another without incurring the excessive costs associated with monitoring the behavior of both parties. Similarly, this same trust facilitates their free exchange of ideas and the willingness to work through difficulties that might be required to result in a mutually beneficial outcome. This trust reserve may apply to customers as well, since they may be more willing to accept product deficiencies as simply being the result of some anomalous event from trustworthy companies, while simultaneously boycotting similar product deficiencies from companies not known to be trustworthy.

Overall, it is clear that companies have a vested interest in seeking to be perceived as ethical by their constituents; but what determines whether or not they are perceived to be ethical? Drawing from the business ethics literature, and the evolving definition of the ethical organization, this study seeks to shed light on this question. To address this question, we examine purpose, practice, and tradition elements of the organization (Collier, 1998). Specifically, we explore the effect of five fundamental dimensions of company ethics that theory suggests might have a significant effect on rater assessments of overall organizational ethics. These are: leadership, climate, human resources, philanthropy and strategic philanthropy.

\subsection{The Influence of Intra-Organizational Variables}

Leadership has been a key variable in organizational ethics theory development and research (Trevino, den Nieuwendoer \& Kish-Gephart, 2014). Leaders play a key role in organizational decision making. They also act as role models and influence subordinates' attitudes and behaviors. Thus, leadership sets the tone for ethical behavior inside an organization, as integrity is thought to flow from the top down, and employees take their cues from management on how to behave (Trevino \& Nelson, 2004). More specifically, the role of the leader in shaping the ethical behavior of others in the organization is impacted by both how employees view the leader's personal morality and how they view her or his ethical leadership behavior (Trevino, Brown \& Pincus-Hartman, 2003; Trevino, Hartman \& Brown, 2000). The leader is often the public face of the organization. Therefore, a positive ethical image of the leader may influence external, as well as internal constituents. Given the primary role of leadership, we hypothesized that leadership, defined in terms of both personal morality and in terms of explicit ethical management behavior, would have a main effect on raters' assessments of the 'ethical organization.'

We included organizational climate and human resources because of the fundamental role these processes and codes have on establishing standards for organizational conduct. Ethical climates are characterized by environments where employees feel free to express themselves without fear of retribution, where they feel free to admit mistakes, and where coworkers are generally cooperative and supportive of one another. These caring environments have been associated with employee attitudes such as commitment and satisfaction (Martin \& Cullen, 2006).

These types of environments are thought to enhance the ethical behavior of employees because potential ethical problems are discussed openly, employees feel no pressure to cover up mistakes, and employees can speak out about any ethical issues they might have without fearing negative consequences to themselves. Prior research suggests the importance of the ethical climate on employee attitudes and work unit unethical behavior (Arnaud \& Schminke, 2012). Thus, we believe that the climate of the organization as understood by the external constituencies will also affect perceptions of the ethical organization. Specifically, we hypothesize that an ethical climate will have a positive main effect on the individual's assessments of the 'ethical organization.' Further, given the role of leaders in shaping the ethical climate of an organization in terms of establishing policies and formal communications that might result in significant effects on the resultant climate, we expect leadership and climate to interact such that high ethical leadership and a strong ethical climate together would yield higher rater assessments of the 'ethical organization' than would either main effect alone.

The final intra-organizational factor we examine is human resource practices. Company policies and practices that govern entry, retention, reward, and dismissal of staff establish an expected and accepted code of behavior. These codes of behavior are strengthened via performance measurement standards and training programs. To the extent that these policies, practices, and codes of acceptable behavior are aligned and support ethical behaviors, they are expected to promote ethical behavior inside the organization. For example, companies that place their corporate values in recruiting literature send a signal to potential applicants that ethical behavior is stressed inside the organization. Similarly, selection systems may be designed to identify and to hire individuals likely to adhere to company values. When aligned, performance appraisal and reward systems then motivate employees to not just achieve their performance objectives but to do so ethically and in a manner consistent with the stated corporate values. Clearly, human resources policies and practices may vary in the degree to which they serve to motivate and reward ethical behavior inside the organization. The internal effects of the ethical infrastructure on attitudes and behaviors have been demonstrated (Trevino, den Nieuwenboer, \& Kish-Gephart, 2014). We expect these consistent, 
positive, albeit small effects to emerge when examining the external constituency's assessment of the ethical organization. Specifically, we hypothesize that human resources policies and practices designed to emphasize ethical behavior will have a main effect on rater assessments of overall organizational ethics.

\subsection{The Influence of Corporate Philanthropy}

Corporate philanthropy refers to activities that promote the general welfare of societal members and is generally considered to be discretionary for the organization. Examples of philanthropy include activities such as making donations to local charities, supporting employee volunteerism, and engaging in service to society. The face validity of the importance of this variable in determining external constituents' perceptions of the ethical organization is clear. However, in Carroll's (1991) pyramid of organizational responsibility, he proposed that organizations have a baseline responsibility to make a profit while adhering to all legal requirements in this pursuit. A second-order responsibility is to behave ethically by treating all stakeholders fairly and to uphold their rights. According to Carroll, philanthropy is a third-order obligation. In other words, according to this view, failing to give back through philanthropic initiatives would not be considered unethical. Yet, members of society increasingly expect organizations to engage in these activities (Porter \& Kramer, 2006). Specifically, we hypothesize that even though philanthropic activities of the organization might be conceptually unrelated to their ethical behavior, as a practical matter, these are visible to the external constituency and will serve to enhance an organization's ethical profile. Accordingly, we expect for philanthropy to have a main effect on rater judgments of overall organizational ethics.

There is a second type of philanthropy, strategic philanthropy, which refers to the carefully chosen philanthropic initiatives that enable the company to incur a direct or indirect benefit from its charitable activities. Strategically choosing only initiatives that benefit the company may be seen as selfish by the external constituency. This strategic perspective may taint the gift and the giver. As a result, it may have a deleterious effect on perceptions of the ethical organization. Yet, giving back with a view toward accruing benefits to both society and the business may well be viewed favorably (Murray, 2015; Porter \& Kramer, 2006; Saiia, Carroll \& Buchholtz, 2003). Strategic philanthropy benefits society, and the business value does not necessarily negate that good. Furthermore, strategic philanthropy may be the surest path to offering long-term sustainable solutions to many of society's problems (i.e., donating technology to colleges in hopes that future graduates will fill a labor shortage for the company; Murray, 2015; Porter \& Kramer, 2006; Saiia, et al., 2003). As such, strategic philanthropy would positively affect assessments of organizational ethics. Due to the pressure on organizations to give back and the popularity of phrases like "doing well by doing good," we believe that constituencies would adopt the latter perspective; therefore, we expect it to have a positive main effect on rater assessments of overall organizational ethics.

In addition to assessments of organizational ethics, we examine likelihood of recommending the organization for an ethics award. While we anticipate a high correlation between these two variables, we also expect differences - particularly as they relate to philanthropy and strategic philanthropy. We predict all five variables to have a positive main effect on assessments of generalized organizational ethics. For recommendations for the ethics award; however, we predict philanthropy and strategic philanthropy will have a greater impact than what they had on overall assessments of organizational ethics. We expect raters to more closely consider philanthropy and the strategic motivation (or lack thereof) behind it when recommending companies to receive awards in ethics precisely because of its more discretionary nature. In short, we believe that raters will feel philanthropy and strategic philanthropy are less important than other factors when assessing whether or not a company is behaving ethically. However, to be deserving of an award for ethics, organizations are expected to do more-like engage in philanthropy.

\section{Method}

\subsection{Sample and Procedure}

In the design of this policy capturing study, we relied on the published work of Scherer, Schwab and Heneman (1987). We chose to perform convenience sampling due to its ease of use and because we seek to generalize our results to the broader population rather than to a specific one (like managers). We had 20 participants consisting of 13 males and 7 females with an age range from 28 to 71 (average age 49.2). Participants also had anywhere from 0 to 45 years of self-reported professional work experience (average experience 17.7 years). All potential participants were sent an introductory letter asking them to participate in a study seeking to learn how individuals go about making evaluations on corporate ethics. If, after reading the introductory letter, the participant chose to continue, he or she was sent a packet of information that contained the experimental materials. These materials contained a background story on the meaning of the company profiles they were being asked to evaluate, the rating scales for our two dependent variables, and the 108 company profiles. 
The background information given to each participant stated that the companies in the study had all agreed to be examined by a team trained in evaluating the ethical characteristics of businesses. Further, participants were told that this "team" had spent many hours investigating each company very closely: conducting extensive interviews and observing day-to-day practices. Based on this extensive and in depth exploration, the team wrote a detailed analysis of each company. In the materials, it was explained to participants that these detailed analyses included global assessments of each firm on five dimensions (leadership, ethical climate, human resources, philanthropy and strategic philanthropy) on a scale of one to ten, where $1=$ very low on the dimension and $10=$ very high on the dimension.

After reading the background story, participants were instructed to review the definition of each dimension before continuing. We told them that the team used the following definitions when making their global assessments:

- Ethical Leadership: the degree to which senior leaders are themselves ethical individuals, make decisions according to ethical principles, hold high standards for ethical behavior in the companies they lead and enforce those ethical standards swiftly and fairly.

- Ethical Climate: the degree to which the organizational members are collaborative and supportive of one another; their work environment is such that everyone feels free to express themselves without fear, and employees feel free to admit mistakes or seek help when needed.

- Human Resources: the emphasis on ethics in the company's formal recruiting, selection, performance appraisal, training and reward systems; company ensures results are achieved in an ethical way.

- Philanthropy: degree to which the company engages in activities designed to help the broader society; encourages employees to engage in these activities; takes steps to support employee volunteerism and service to society; provides significant company resources aimed at improving the broader community.

- Strategic Philanthropy: degree to which the company engages in philanthropic initiatives that involve utilizing the company's core resources and capabilities and results in benefits to the company as well as society.

Participants were then instructed to review the expert ratings of each firm and then make their own evaluative judgments on the ethical behavior of each firm. These evaluative judgments served as the dependent variables in this study. Specifically, participants were asked to rate on a scale of one to seven ( $1=$ not at all; $7=$ very much) how ethical each company was overall and how likely the participant was to recommend that the company receive an award for excellence in ethical practices.

The five independent variables were operationalized as follows:

1. Ethical Leadership. Ethical leadership had two levels, average and superior. On a scale of 1 to 10 , average leadership equaled a 5 or 6 . Superior leadership equaled 9 or 10 .

2. Ethical Climate. Ethical climate had two levels, average and superior. On a scale of 1 to 10 , average ethical climate equaled a 5 or 6 . Superior ethical climate equaled 9 or 10.

3. Human Resources. Ethics in human resources had three levels, low, average and superior. On a scale of 1 to 10, low ethics in human resources equaled 1 or 2. Average ethics in human resources equaled 5 or 6. Superior ethics in human resources equaled 9 or 10.

4. Philanthropy. Philanthropy had two levels, average and superior. On a scale of 1 to 10 , average philanthropy equaled 5 or 6 . Superior philanthropy equaled 9 or 10.

5. Strategic Philanthropy. Strategic philanthropy had two levels, low and high. On a scale of 1 to 10, low strategic philanthropy equaled 1 or 2. High strategic philanthropy equaled 9 or 10.

The information on these independent variables was presented to participants in the form of brief company profiles. After each company profile, space was given for participants to make their ratings on each of our dependent variables. For example, one company profile read:

The Ethical Leadership score was 9.

The Ethical Climate score was 6.

The Ethics in Human Resources score was 9.

The Philanthropy score was 10.

The Strategic Philanthropy score was 9. 
Following the experimental design of Sherer et al. (1987), the five independent variables were crossed and balanced to create 48 company profiles. Six additional company profiles were created that consisted of similar information to those under investigation; however, the "expert ratings" in these profiles were different from the levels we manipulated and investigated. This was done to add additional realism to the experimental materials. We created a second set of these company profiles as a means to examine the intrarater reliability of rater policy and as a means to increase the power to detect any interaction effects. Overall, this resulted in 108 company profiles (two sets of 48 plus a total of 12 filler profiles) for raters to evaluate.

The profiles were ordered randomly and then rearranged slightly to ensure that the first two variables (ethical leadership and ethical climate) were not both at the exact same level when adjacent to one another. This was done to reduce the possibility of raters making comparative judgments instead of evaluating each profile on its own merit. At the bottom of each profile, raters made their ratings of each of the two dependent variables. Finally, after rating all 108 company profiles, raters were asked to rank each of our independent variables in order of its importance in determining their overall organizational ethics scores. This was done so that a comparison can be made between raters' perceptions of the importance of each dimension in determining their overall evaluations with the results from our statistical analysis of their actual rating policies (Sherer, et al., 1987).

\subsection{Analyses}

We used two dependent variables in this study: overall organizational ethics evaluation and rater likelihood of recommending the organization for an ethics award. It was expected that though they would not be perfectly correlated, there would be a high correlation between the two, as they both are expected to capture an overall evaluation of an organization's ethical profile.

An initial analysis to estimate the intrarater reliability of participant responses was performed by calculating, for each participant, the correlation between their ratings made on overall organizational ethics (and award recommendations) for the first 48 company profiles with those made on the corresponding duplicate profiles. High correlations between ratings made on the 48 company profiles and their duplicate profiles would provide some evidence that raters did not change their policies throughout the experimental exercise. It would also provide some evidence that evaluations of company profiles were made independently, as steps were taken to ensure that similar profiles were not placed adjacent to one another (Sherer, et al., 1987).

Following Sherer et al. (1987), multiple regression techniques were used to capture the rating policies used by participants when making judgments on our two dependent variables. The five independent variables were set up as orthogonal contrasts and each dependent variable was regressed on the five main effect variables and their ten possible interaction variables. In total, 40 regressions were performed ( 2 for each of 20 participants). The standardized regression coefficients can then be interpreted to indicate the direction and importance of each variable on rater decisions on overall organizational ethics and on their inclination to reward organizational ethics (Sherer, et al., 1987).

Finally, the consistency between the results of our policy capturing study and the direct rankings provided by participants was calculated. This was done by first rank ordering the five main effect standardized regression coefficients for each participant and then correlating these with the self-report rankings using Spearman's rank-order procedure (Sherer, et al., 1987).

\section{Results}

The correlation between the two dependent variables, overall ethics evaluation and rater likelihood of recommending the organization for an ethics award was $\mathrm{r}=.88$. The preliminary analysis conducted to calculate the intrarater reliability of the participants' dependent variable ratings revealed an average intrarater reliability of $r=.83$ for overall organizational ethics ratings and $\mathrm{r}=.81$ for ethics award decisions. These findings suggest that the policies of participant ratings were stable throughout the exercise and are similar to those found in other policy capturing studies (Sherer, et al., 1987; Rynes, Schwab \& Heneman, 1983).

The results of our policy capturing study for rater evaluations on overall organizational ethics are presented in Table 1. 
Table 1. The standardized regression coefficients for participants on the overall assessment of organizational ethical behavior dependent variable

\begin{tabular}{cllcccc}
\hline Participant $^{\mathrm{a}}$ & Leadership & Climate & $\begin{array}{c}\text { Resources } \\
\text { Philanthropy }\end{array}$ & $\begin{array}{c}\text { Strategic } \\
\text { Philanthropy }\end{array}$ & $\mathrm{R}^{2}$ \\
\hline 1 & 0.11 & $0.21^{*}$ & 0.21 & $0.23^{*}$ & $0.41^{* *}$ & 0.78 \\
2 & $0.25^{*}$ & $0.28^{*}$ & -0.06 & $0.38^{* *}$ & $0.42^{* *}$ & 0.71 \\
3 & $0.46^{* *}$ & $0.32^{* *}$ & $0.34^{* *}$ & 0.02 & 0.05 & 0.79 \\
4 & $0.53^{* *}$ & $0.43^{* *}$ & 0.15 & $0.50^{* *}$ & $0.22^{*}$ & 0.79 \\
5 & $0.71^{* *}$ & 0.05 & 0.01 & 0.06 & $0.22^{*}$ & 0.77 \\
6 & $0.39^{* *}$ & $0.24^{*}$ & $0.47^{* *}$ & $0.22^{*}$ & 0.19 & 0.78 \\
7 & $0.53^{* *}$ & $0.48^{* *}$ & $0.37^{* *}$ & -0.05 & 0.10 & 0.81 \\
8 & $0.45^{* *}$ & $0.47^{* *}$ & $0.44^{* *}$ & 0.11 & 0.00 & 0.80 \\
9 & $0.63^{* *}$ & $0.48^{* *}$ & 0.03 & 0.20 & $0.37^{* *}$ & 0.67 \\
10 & $0.45^{* *}$ & $0.54^{* *}$ & $0.30^{* *}$ & $0.67^{* *}$ & $0.59^{* *}$ & 0.83 \\
11 & $0.51^{* *}$ & $0.64^{* *}$ & 0.10 & $0.21^{*}$ & 0.04 & 0.78 \\
12 & $0.44^{* *}$ & $0.42^{* *}$ & $0.35^{* *}$ & $0.42^{* *}$ & $0.42^{* *}$ & 0.75 \\
13 & $0.41^{* *}$ & $0.29^{*}$ & $0.50^{* *}$ & 0.21 & 0.16 & 0.68 \\
14 & $0.82^{* *}$ & 0.00 & -0.02 & 0.17 & $0.23^{*}$ & 0.83 \\
15 & $0.67^{* *}$ & $0.67^{* *}$ & 0.05 & $0.57^{* *}$ & 0.16 & 0.83 \\
16 & $0.62^{* *}$ & $0.62^{* *}$ & -0.05 & 0.05 & 0.00 & 0.90 \\
17 & 0.22 & 0.13 & $0.37^{*}$ & 0.24 & $0.50^{* *}$ & 0.58 \\
18 & $0.53^{* *}$ & $0.36^{* *}$ & $0.64^{* *}$ & $0.31^{* *}$ & 0.13 & 0.79 \\
19 & 0.14 & 0.17 & 0.07 & 0.18 & $0.38^{* *}$ & 0.75 \\
20 & $0.65^{* *}$ & $0.38^{* *}$ & $0.67^{* *}$ & 0.15 & $0.20^{*}$ & 0.81 \\
Partial $\mathrm{R}^{2}$ & 0.23 & 0.16 & 0.07 & 0.08 & 0.07 & \\
\hline & & & & & &
\end{tabular}

${ }^{\mathrm{a}} \mathrm{n}=96$ for each participant

${ }^{*} \mathrm{p}<0.05$

${ }^{* *} \mathrm{p}<0.01$

It shows standardized regression coefficients of all independent variables main effects for each of twenty participants. The bottom row shows the average proportion of variance explained by the variable in determining overall organizational ethics decisions. For example, the effect of ethical leadership was significantly related to ratings of overall organizational ethics for 17 of the 20 respondents, and it accounted for, on average, $23 \%$ of the variance. Similarly, the effect of ethical climate was significant for 16 of the participants and accounted for, on average, $16 \%$ of the variance in overall organizational ethics decisions. The effects of ethical human resources, philanthropy and strategic philanthropy were statistically significant for about half of the participants (ten, nine and eleven participants, respectively) and accounted for lesser, though non-trivial, amounts of variance in overall organizational ethics decisions ( $7 \%, 8 \%$ and $7 \%$, respectively). Viewed collectively, our hypotheses regarding the significance of the main effects of each independent variable were generally supported.

The main effects shown in Table 1 accounted for an average of $61 \%$ of the variance in raters' decisions on overall organizational ethics. However, across the 20 participants, $\mathrm{R}^{2}$ values ranged from a low of $58 \%$ to a high of $90 \%$. Further, there was significant variation across participants in the relative importance they placed on each of the independent variables in making their overall organizational ethics rating. For example, participant 10 used 
information about all 5 independent variables when making decisions on overall organizational ethics, while participant 19 used only the information on strategic philanthropy.

We had hypothesized a significant interaction effect between ethical leadership and ethical climate; however, this was true in only 4 instances, and this interaction accounted for only $2 \%$ of the variance in overall organizational ethics decisions. The interaction between ethical climate and ethical human resources was also significant in 4 instances, and this interaction accounted for only $3 \%$ of the variance. All other interactions were significant for only one rater (or none) and accounted for trivial amounts of variance explained in overall organizational ethics decisions. Therefore, our results failed to support the interaction hypothesis.

The results for rater decisions on recommending companies for an award for ethics are presented in Table 2 .

Table 2. The standardized regression coefficients for participants on the recommendation for an ethics award dependent variable

\begin{tabular}{|c|c|c|c|c|c|c|}
\hline Participant $^{\mathrm{a}}$ & Leadership & Climate & $\begin{array}{c}\text { Human } \\
\text { Resources }\end{array}$ & Philanthropy & $\begin{array}{c}\text { Strategic } \\
\text { Philanthropy }\end{array}$ & $\mathrm{R}^{2}$ \\
\hline 1 & 0.08 & 0.17 & 0.17 & $0.21 *$ & $0.38^{* *}$ & 0.82 \\
\hline 2 & $0.37 * *$ & $0.37 * *$ & -0.08 & $0.48 * *$ & $0.54 * *$ & 0.76 \\
\hline 3 & $0.40 * *$ & $0.27 * *$ & $0.28 *$ & $0.25 *$ & $0.27 * *$ & 0.79 \\
\hline 4 & $0.58 * *$ & $0.41 * *$ & $0.25 *$ & $0.54 * *$ & $0.32 * *$ & 0.79 \\
\hline 5 & $0.60 * *$ & 0.11 & -0.06 & 0.17 & $0.29 * *$ & 0.77 \\
\hline 6 & $0.30 * *$ & $0.27 * *$ & $0.59 * *$ & $0.51^{* *}$ & $0.41 * *$ & 0.81 \\
\hline 7 & $0.53 * *$ & $0.48 * *$ & $0.37 * *$ & -0.05 & 0.10 & 0.81 \\
\hline 8 & $0.36^{* *}$ & $0.43^{* *}$ & $0.42 * *$ & $0.37 * *$ & $0.36^{* *}$ & 0.80 \\
\hline 9 & $0.44 * *$ & $0.44 * *$ & 0.06 & $0.40 * *$ & $0.32 * *$ & 0.70 \\
\hline 10 & $0.37 * *$ & $0.37 * *$ & $0.28 * *$ & $0.64 * *$ & $0.52 * *$ & 0.83 \\
\hline 11 & 0.21 & $0.43^{* *}$ & $0.34 * *$ & $0.41 * *$ & $0.38^{* *}$ & 0.76 \\
\hline 12 & $0.42 * *$ & $0.40 * *$ & $0.32 *$ & $0.40 * *$ & $0.36^{* *}$ & 0.75 \\
\hline 13 & $0.40 * *$ & $0.25^{*}$ & $0.31 *$ & 0.17 & 0.17 & 0.74 \\
\hline 14 & $0.39 * *$ & -0.09 & -0.09 & 0.20 & 0.17 & 0.68 \\
\hline 15 & $0.49 * *$ & $0.73 * *$ & 0.09 & $0.58 * *$ & $0.24 * *$ & 0.86 \\
\hline 16 & $0.48 * *$ & $0.44 * *$ & -0.02 & 0.11 & $0.22 * *$ & 0.90 \\
\hline 17 & 0.18 & 0.15 & 0.24 & 0.18 & $0.43 * *$ & 0.57 \\
\hline 18 & $0.30^{* *}$ & 0.20 & $0.40^{* *}$ & $0.63 * *$ & $0.58 * *$ & 0.76 \\
\hline 19 & 0.08 & 0.18 & -0.04 & $0.25^{*}$ & $0.28 *$ & 0.73 \\
\hline 20 & $0.68 * *$ & $0.33^{*}$ & $0.55 * *$ & $0.35 * *$ & $0.30^{*}$ & 0.65 \\
\hline \multicolumn{7}{|l|}{ Partial $\mathrm{R}^{2}$} \\
\hline Average & 0.16 & 0.13 & 0.07 & 0.14 & 0.12 & \\
\hline
\end{tabular}

Because of the high correlation between our two dependent variables, it is not surprising that some results for award recommendations are somewhat similar to those decisions on overall organizational ethics. For instance, the effect of ethical human resources accounted for $7 \%$ of the variance in award decisions as it did with overall organizational ethics decisions. Similarly, ethical leadership accounted for the highest percentage of variance explained in award decisions, though the percentage was reduced from $23 \%$ to $16 \%$. Further, as in the case for overall organizational ethics decisions, there was a great deal of variation among raters in the importance placed on each independent variable in making their decisions on award recommendations.

We did, however, find some differences in the impact of philanthropy and strategic philanthropy on rater ethics award recommendations. We had hypothesized that raters would take into account these variables when making ethics award decisions more so than when they were just considering the degree to which an organization behaves 
ethically. Comparing the results presented in Table 1 and Table 2 show that this was the case. The effect of philanthropy on rater ethics award decisions was significant for 14 of the 20 raters (compared to only 9 raters when making their judgments on overall organizational ethics), and the proportion of variance explained by philanthropy on rater ethics award decisions was $14 \%$ (compared to $8 \%$ for overall organizational ethics). A similar pattern was shown for strategic philanthropy. While 11 participants considered strategic philanthropy when making overall organizational ethics decisions, this rose to 17 for those who considered this variable when making ethics award recommendations. Strategic philanthropy also explained $14 \%$ of the variance in ethics award recommendations while explaining only $7 \%$ of the variance in overall organizational ethics judgments.

Results on the importance of the five independent variables found in our policy capturing study compared to the rankings that participants self-reported were $\mathrm{r}=.50$ for overall organizational ethics and $\mathrm{r}=.44$ for ethics award recommendations.

\section{Discussion}

Much has been written about intra-organizational perspectives of organizational ethics while virtually ignoring the perceptions of those outside the organization. Yet these perceptions are critically important to organizations as they are affected by an increasingly demanding and sometimes contentious society. This study was designed to shed light on how individuals account for ethical leadership, ethical climate, ethical human resource practices, philanthropy and strategic philanthropy in making gestalt assessments of the ethical behavior of organizations. Using a policy capturing methodology outlined by Sherer and colleagues (1987), our results indicate that each of these factors has a positive effect on rater overall assessments of organizational ethics and on raters' inclinations to recommend an organization to receive an award for their ethical behavior. In general, the pattern of results suggests that raters weigh the ethical characteristics of an organization's leadership and climate more strongly than the other three variables when diagnosing an organization's overall ethical profile. However, when considering organizations for an award recommendation, raters take into account both philanthropy and strategic philanthropy in roughly equal proportion to leadership and climate. The effect of human resources policies and practices on both overall organizational ethics decisions and decisions on recommending a company for an ethics award was the same. The results were consistent with the research on intra-organizational samples which reported a small, positive relationship between corporate infrastructure and business ethical attitudes and behaviors (Schminke, et al., 2014).

It appears observers of organizational behavior require multiple positive messages about the organization's ethical behavior before assessing it as "ethical." The majority of respondents indicated at least three elements are considered when evaluating overall organizational ethics, and often, four were required to obtain a positive recommendation for an ethics award. The skeptical public has become more discerning when evaluating organizational ethics. We speculate that the slew of negative press has had an effect of the public, whereby richer information is now required before they are willing to label a firm as being ethical.

Perhaps the most interesting finding is the results associated with the role of philanthropy and strategic philanthropy in rater decision-making. Our results revealed that both factors play a significant role in determining assessments of overall organizational ethics for approximately half of the raters. However, these factors mattered more when considering the company for an ethics award ( $70 \%$ and $85 \%$ respectively demonstrated significant main effects). We interpret this pattern to mean that when evaluating an organization's ethical behavior, judges will take into account each of our five independent variables, but recommendations to receive an ethics award would require the company to engage in philanthropic activities in order to distinguish itself. In short, our results are consistent with the idea that philanthropy (whether strategic or not) is discretionary and is less "required" when diagnosing a company's ethical profile. These variables only rise in importance when raters decide whether the organization's ethical behavior is distinct enough to be deserving of an award.

The role of strategic philanthropy in determining rater assessments of organizational ethics is particularly interesting. Over $50 \%$ of participants viewed this as a significant indicator of an ethical organization. Our research supports the arguments of Porter et al. (2009) and others championing social entrepreneurship. They argue philanthropic initiatives should be strategic to incentivize businesses to participate, whereby the organization's self-interest is promoted by engaging in philanthropy. Interestingly, proponents of strategic philanthropy often argue that a key barrier to more strategic philanthropy is the stigma associated with companies benefitting themselves in the process of helping solve societal problems. Our results suggest that, at least for our sample of participants, no such stigma exists. Furthermore, given leadership's fiscal responsibility to stakeholders and ambiguity associated with philanthropy goals, it would seem the strategic philanthropic approach is required for it to be sustainable (Saiia, et al., 2003). 
Finally, a rank order correlation was computed which compared the actual policy capturing findings with the self-reported importance of each of the five ethical dimensions across our 20 participants. Our results were $\mathrm{r}=50$ for overall ethics and $\mathrm{r}=.44$ for ethics award recommendations. These results are consistent with the findings of Sherer and colleagues (1987) who also found that raters are not particularly accurate in assessing the relative importance they place on various attributes when making overall judgments., even when, as in this case, they are asked to rank-order the importance of each attribute immediately following making their global decisions. We believe that the lack of self awareness in this regard makes policy capturing studies such as this one particularly revealing. For instance, relying only on participant self-reports of the importance of strategic philanthropy, organizational decision makers may believe that this dimension is unimportant; as it was ranked last in importance by $70 \%$ of our participants and next to last in importance by $25 \%$ of our respondents. However, when actually making decisions about ethics (particularly when deciding on award recipients), fully $40 \%$ of the raters used strategic philanthropy as one of their top two determinants in making their evaluations.

\subsection{Limitations of This Research}

While our results on the average effects of each of the independent variables reflect an interesting general pattern, interpretation of their average magnitudes against one another is inappropriate for both methodological and substantive reasons. First, our independent variables were artificially manipulated, and it is possible that we may have inadvertently manipulated one or more variables in a way that conveyed stronger or richer information about the dimension(s) to the participant compared to other variables. Further, the order in which the independent variables were presented to the participant through the company profiles might have introduced artificial variance that can obfuscate the true overall relationships among the variables in determining overall organizational ethics decisions. Despite the care taken to reduce these possibilities (carefully creating the definitions of each independent variable and reordering company profiles to guard against raters making comparative judgments) it is still possible, if not likely that, some artifactual variance is built in to our treatment levels. This concern affects importance weights in policy capturing studies such as this one (Sherer, et al., 1987).

A more substantive concern in interpreting the average effect of each variable against one another is the wide disparity across raters in their rating policies in making their decisions on organizational ethics. For example, our overall results show that ethical leadership and ethical climate had higher average effects on rater decisions than did human resources, philanthropy and strategic philanthropy. However, our results suggest that three out of twenty of our participants did not use leadership in making their decisions at all, and four participants did not use ethical climate at all. Similarly, strategic philanthropy (along with human resources) accounted for the smallest percentage of average variance in overall organizational ethics decisions, yet for fully $25 \%$ of our sample, it was the single most important factor in determining their ratings.

\subsection{Future Research}

We capitalized on the autonomous person perspective to examine the effect of leadership, climate, human resources practices and policies, philanthropy, and strategic philanthropy on evaluations of organizational ethics. The literature has not developed a single definition of business ethics, indicating each individual holds a somewhat unique perspective. We allowed our participants to tap into those definitions. We uncovered a fascinating pattern in the development of their mental model of the ethical organization. Nonetheless, future research may seek to assign a uniform definition of business ethics which to date has not emerged in the literature.

The variables included in this research were selected because of their omnipresence in the business ethics literature. However, given our research methodology, a comprehensive inclusion was impossible. Future research may include different or even more variables. Our approach employed very broad definitions, and while the definitions were carefully crafted, we are confident each participant engaged in a bit of "fill in the blanks" with regard to dimensional definitions. Despite this, we find a pattern of results consistent with our hypotheses. Future research may seek to more richly define these dimensions and the precise meaning of each level.

\subsection{Conclusions}

Despite limitations, we have begun an important investigation into how people use information to make assessments of organizational ethics. Organizations may manage communications well internally, but the external stakeholders are also important to survival. Using the information gleaned from our research, we are able to identify important factors in the development of perceptions of organizational ethics.

\section{References}

Arnaud, A., \& Schminke, M. (2012). The ethical climate and context of organizations: A comprehensive model. Organizational Science, 23, 1767-80. http://dx.doi.org/10.1287/orsc.1110.0698 
Carroll, A. B. (1991). The pyramid of corporate social responsibility: Toward the moral management of organizational stakeholders. Business Horizons, 34(4), 39-48. http://dx.doi.org/10.1016/0007-6813(91)90005-G

Collier, J. (1998). Theorising the ethical organization. Business Ethics Quarterly, 8, 621-54. http://dx.doi.org/10.2307/3857544

Johnston, D. C. (1997, November). United Way, faced with fewer donors, is giving away less. New York Times, 9(1).

Kohlberg, L. (1969). Stage and sequence: the cognitive developmental approach to socialization. In DA Goslin (Ed.), Handbook of Socialization Theory and Research (pp. 347-480). Chicago: Rand McNally.

Kohlberg, L. (1981). The philosophy of moral development: Moral stages and the idea of justice. San Francisco: Harper \& Row.

Labitch, K. (1992). The new crisis in business ethics. Fortune, April 20, 167-176.

Martin, K., \& Cullen. (2006). Continuities and extensions of ethical climate theory: a meta-analytic review. Journal of Business Ethics, 69, 175-94. http://dx.doi.org/10.1007/s10551-006-9084-7

Murray, A. (2015). Doing well by doing good. Fortune, 172, 57-74.

Nussbaum, B. (2002). Can you trust anybody anymore? Business Week, January 28, 31-32.

Porter, M., \& Kramer, M. (2006). Strategy \& Society: The link between competitive advantage and corporate social responsibility. Harvard Business Review, 78-92.

Rynes, S., Schwab, D., \& Heneman, H. (1983). The role of pay and market pay variability in job application decisions. Organizational Behavior and Decision Processes, 31, 353-364. http://dx.doi.org/10.1016/0030-5073(83)90130-7

Saiia, D., Carroll, A., \& Buchholtz, A. (2003). Philanthropy as strategy: When corporate charity "begins at home." Business and Society, 42, 169-201. http://dx.doi.org/10.1177/0007650303042002002

Schminke, M., Caldwell, J., Ambrose, M., \& McMahon, S. (2014). Better than ever? Employee reactions to ethical failures in organizations, and the ethical recovery paradox. Organizational Behavior and Human Decision Processes, 123, 206-19. http://dx.doi.org/10.1016/j.obhdp.2013.10.002

Sherer, P., Schwab, D., \& Heneman, H. (1987). Managerial salary-raise decisions: A policy capturing approach. Personnel Psychology, 40, 27-38. http://dx.doi.org/10.1111/j.1744-6570.1987.tb02375.x

SHRM. (2015). Employee job satisfaction and engagement: Optimizing organizational culture for success. Publication \# 15-0133.

Trevino, L. K., \& Nelson, K. (2004). Managing business ethics: Straight talk about how to do it right. Hoboken: John Wiley \& Sons.

Trevino, L. K., Brown, M., \& Pincus-Hartman, L. (2003). A qualitative investigation of perceived executive ethical leadership: Perceptions from inside and outside the executive suite. Human Relations, 56(1), 5-37. http://dx.doi.org/10.1177/0018726703056001448

Trevino, L. K., den Nieuwenboer, N. A., \& Kish-Gephart, J. J. (2014). (Un)Ethical behavior in organizations. Annual Review of Psychology, 65, 635-60. http://dx.doi.org/10.1146/annurev-psych-113011-143745

Trevino, L. K., Hartman, L. P., \& Brown, M. (2000). Moral person and moral manager: How executives develop a reputation for ethical leadership. California Management Review, 42(4), 128-142. http://dx.doi.org/10.2307/41166057

Trudel, R. C. J. (2004). Do corporate ethics affect consumer purchase decisions? Simon Fraser University Master's Thesis. 